By neutralising the acid products and thus assisting in their elimination their action is in harmony with our view. Salicylates above all drugs are specifics of rheumatism and are said to be useful in diabetes. We firmly believe that they are strongly indicated in rickets, though as yet we have had few opportunities of estimating their value. On our hypothesis they are of value in the treatment of rhenmatism because they combine with that atomic group which in the break-up of the biogen molecule is a fore stage of lactic acid, glycocene, and perhaps other bodies. ${ }^{3}$

$$
\begin{aligned}
& \mathrm{C}_{6} \mathrm{H}_{4}\left\{\begin{array}{l}
\mathrm{OH} \\
\mathrm{COOH}
\end{array}+\mathrm{CH}_{2}\left\{\begin{array} { l } 
{ \mathrm { OH } } \\
{ \mathrm { CN } = \mathrm { C } _ { 6 } \mathrm { H } _ { 4 } }
\end{array} \left\{\begin{array}{l}
\mathrm{OH} \\
\mathrm{CNOH} \\
\mathrm{COOH}
\end{array}\right.\right.\right. \\
& \begin{array}{c}
\text { Salicylic Methene } \\
\text { acid. }
\end{array} \quad \begin{array}{c}
\text { Salicyluric } \\
\text { acid. }
\end{array}
\end{aligned}
$$

They are of less value in diabetes because the entire dextrose molecule is separated from the biogen molecule and requires no neutralisation. They are of value in such cases by preventing the formation of certain by-products which are usually found in company with dextrose in the urine. With regard to the use of salicylates it must be remembered that the maximum effect is only obtained when they are given in large doses; large doses would obviously be required if our view is correct.

In the attempt which we have made to establish a causal connexion between excessive carbohydrate ingestion and the incidence of disease we have avoided for the most part making an appeal to the evidence derived from clinical experience. Our reason for this obvious omission is that our complete recognition of the essential features which underlie the theory which we have advanced, is of such recent growth that we have not yet had time to accumulate clinical testimony in sufficient amount to carry weight in support of our contention. Nevertheless, the observations which we have thus far been enabled to make on the clinical side of the subject are in complete harmony with the conditions which on theoretical grounds we should expect to obtain. Furthermore, we may point to the clinical experience of such keen and original observers as Rabagliati and Keith which lends strong support to the views which we have enunciated. Rabagliati gives convincing proofs of the evils which may be wrought by the over-ingestion of carbohydrates, and Keith, in his advocacy of the therapeutic efficacy of starvation (so-called) in the treatment of disease, supplies indirect evidence in support of our contentions.

Although we have endeavoured to clearly distinguish between the condition known as lithæmia or gout, and the one we have termed glycosachthæmia, we have not attempted to indicate the effects which might be produced by the possible action and interaction of their respective metabolites. That such reaction and inter-action between the metabolites of these conditions does take place there can be little doubt with the production of disease, which in its pathological significance combines in varying degrees the features common to lithrmia on the one hand and glycosachthæmia on the other.

Although it cannot be asserted that we have advanced any convincing proof of the existence of the condition which we have termed glycosachthæmia we venture to hope that the evidence which we have brought forward will serve to stimulate other observers to investigate the subject. For our own part we feel convinced that further inquiry will serve to strengthen the views which we have advanced in this paper and to establish the theory of glycosachthæmia on a firm foundation of fact.

3 P. W. Latham : Croonian Lectures, 1886.

Brentry HoMe For Inebriatas. - At the meeting of the Gloucestershire County Council held on July 10th it was reported that this home was now contributed to by 23 county and borough councils to the extent of $£ 25,000$. This involved a provision of 104 beds for women and 73 for men. When their arrangements were completed there would be 183 beds against the required 177 . Ep to the present 58 cases had been admitted.

CARdifF INFIRMARY.-At a meeting of the Executive Committee of the Cardiff Infirmary, held on Jaly 17th, it was decided to recommend to the governors of that institution that the appointrment of general superintendent be vested in the resident medical officer and that the duties of the secretary be solely confined to secretarial and financial work.

\section{THE WAR IN SOUTH AFRICA: JOTTINGS IN BURGHERSDORP. ${ }^{1}$}

BY HERBERT OAIGER, M.B. LOND., F.R.C.S. ENG.

I WAS in Burghersdorp during the Boer occupation of the town and saw a number of the wounded after the battle of Stormberg.

The Batthe at Stormberg, Dec. 10Th, 1899.

At this battle General Gatacre's forces met with a serious defeat, losing 650 men as prisoners. About 70 of these prisoners were wounded and they passed through Burghersdorp on their way to Bloemfontein. 24 of them were kept at Burghersdorp for a month or more in an extemporised hospital arranged by the British residents at the request of the Free State authorities. Many of the wounds were trifling in nature, and 18 of these men marched 20 miles from Stormberg to Burghersdorp on the day following the battle and the remainder were brought to Burghersdorp by ox wagons at different dates. Half of these would be fit for service within a month. The transport by ox wagon was bitterly complained of, the jolting over the rough roads having caused much aggravation of painful wounds. One man's chest was blistered by the heat of the sun, the wagons being uncovered. The wounded officers were brought to Burghersdorp in covered carts. The wounded men spoke well of the treatment which they had received from their Dutch captors at Stormberg.

On the battlefield the men were attended by two medical men who went out from Burghersdorp on the chance of being of some use. The men were anxious to know whether they would be attended by English practitioners, and they were very pleased to hear that there were none but English medical men in Burghersdorp. The nursing in the hospital was done by English (male) residents and refugees from the Republics. The school building was used for the hospital and came to be used more or less as a club as most of the Englishmen of the place met there, as it was almost the only place, with the exception of the private houses, where it was considered safe to speak freely. The amateur male nurses worked well in watches of three hours at a time. There were but few cases which required skilled nursing. Lord Roberts subsequently wrote to the mayor of the town thanking the British residents of Burghersdorp for all that had been done for the wounded and prisoners who passed through the town.

An interesting cerebral case.-A private who had been shot through the head completely lost his memory of events preceding the battle. There was no paralysis. A Mauser ballet had entered at the outer end of the left eyebrow and had passed out on a level with the occipital protuberance about an inch to the left. When seen 10 days after the wound of entrance was perfectly healed and difficult to see. The exit wound was still covered by a small scab. He had a dazed look, and when asked questions would reply, "I cannot rightly mind that, sir." He remembered one thing in his past life. He said that he was married and that his wife was married too. This latter statement he is said to have reiterated again and again shortly after the battle. With this exception he remembered nothing of his past history, and did not regain his memory up to the time when he left for Bloemfontein, 40 days after the injury. His memory for events after the battle seemed to be fairly good.

Nerve injuries. - The men who seemed to suffer most and longest were those who had wounds involving nerve trunks. I had three of these patients under my care for several weeks, and it was sad to see the agonies they suffered. Morphia in large doses was the only thing that gave any relief to the pain. A sergeant had an oblique flesh wound of the thigh which healed by first intention, but pain came on about 14 days after the injury. He had had severe hæmorrhage immediately after receiving the wound which he stopped by means of an improvised tourniquet which was left on for 36 hours. Possibly this may have had something to do with the causation of the pain. The pain was felt in the outer side of the leg below the knee and in the toes. There was no evidence of any paralysis, and, indeed, the man had been up and about for several days before the pain

1 An abstract of Dr. Herbert Caiger's article which appears in the August number of the Phonographic Record of Clinical Teaching sord Medical Science. 
came on. The pains continued for a long time and were still very severe when he wrote from Cape Town in April. No operation was done. In the two other cases there was marked paralysis and wasting of muscles. In one some cord of the brachial plexus was probably injured, and in the other the median and ulnar nerves were injured by a wound about the middle of the arm. In both these cases the pain came on on the day of the battle and was intense from the first. The operation in one of the cases was performed at Bloemfontein, and with relief to the pain.

Fatal mental disease following scvere wounds.-An officer was wounded by shrapnel fired by our own artillery. The nature of the wounds necessitated amputation of one leg and some of the fingers of each hand; he had also several wounds of the trunk, and for some time was not expected to live. He recovered so far, however, that he was removed to the hospital at Burghersdorp some weeks after the battle. The wounds healed completely, but he continually brooded over the disaster at Stormberg, which troubled him much more than the mutilation he had suffered from, and at length he died from acnte mania. Shortly before bis death the Free State Government had granted his release in return for a wounded commandant who had lost one of his legs after the battle of Elandslaagte and was released by Lord Roberts. The officer was dying when the news of his release arrived and he could not be moved. His body was taken back to the British lines where he was buried by his comrades with military honours. This was the only death which occurred among the wounded prisoners who were brought back to Burghersdorp from the battle of Stormberg.

Septic cases. - The proportion of septic cases to the whole number of wounded was small. The worst case was a wound involving the mouth. The bullet entered at the angle of the mouth and passed backwards and slightly downwards, emerging at the back of the neck about an inch from the middle line. It had plonghed along the inside of the cheek, knocked out a lower molar, broken some fragments off the lower maxilla (which came away at a later date), and perforated the posterior wall of the pharynx. This man's mouth was in such a foul condition when he arrived at Burghersdorp, four days after the battle, that he had to be placed in a separate ward. After the separation of some very foul sloughs the mouth wounds healed, but he then developed a deep abscess in the sub-maxillary region. This was opened just before he left for Bloemfontein, nearly six weeks after the battle. Many of the wounds were inflicted by Martini-Henry bullets, and, of course, the wounds were more severe than those caused by Mauser bullets and a greater number of them suppurated. Many of the shrapnel wounds, on the other hand, remained quite aseptic. A compound fracture of the lower end of the ulna from a shrapnel bullet, which was under my care, did perfectly well.

Physique of THE Boers.

I have had the experience of six years' practice among the Boers of the Jacobsdal and Burghersdorp districts, and am of opinion that in comparing the Boers with Tommy Atkins the advantage is on the side of Tommy. The Boers are more used to out-of-door life and irregular meals, they suffer less from syphilis, and they are more independent and more accustomed to act on their own responsibility, but, on the other hand, although the average age might not be very different, the Boer ranks include many below as well as above the age limits which obtain in the British army. I have seen a boy of 11 years of age brought by his father on commando from the Free State. There were many under 16 and 17 years of age, and many over 40 years of age. Men suffering from organic disease, such as of the heart, which would unfit them for any unusual fatigne went on commando. The Boers who were commandeered in the district in which I lived were not subjected to any medical examination to prove their fitness for service, and in one case I gave a certificate of unfitness for service to a man with phthisis partially arrested but still with extensive signs in one lung, but the certificate was disregarded by the officials and the man was sent to the front, where he took part in a reconnaissance which took up 22 hours and completely knocked him ap. A few days later the man obtained another certificate from a Free State surgeon, for which he paid a guinea, and was then allowed to return home.
Stormberg was bad generalship. The men were tired out before the fight began. During the retreat, after the battle, many of the men are said to have dropped down and fallen asleep from sheer fatigue. It is said that many who were taken prisoners there were found lying fast asleep in their trenches. The prisoners told us that they had marched all the night before the battle and had had very little sleep during the preceding night. Notwitbstanding this, and the fact that all the advantages of position were with the enemy, some of the Boers themselves admitted that our men had made a good fight. Had it not been for the loss of their leaders at a critical moment through the mistake of our own artillery, many think that the result of the battle would have been very different. Of course, on special occasions men must have severe strain put on their powers of endurance, but there is a limit, and from all I have heard this limit was much exceeded in the operations ending in the battle of Stormberg. Further, I have heard that it was the practice of the officer commanding a regiment recently stationed in this neighbourhood very frequently in the mornings to take the men a long march to the top of some stiff hill before breakfast, bringing them back so fatigued that when breakfast time arrived many of them had no appetite for it. This sort of thing would be well enough once in a way, but to make a frequent practice of over-fatigning the men before they have had any food would hardly improve their fitness for service.

SANITARY ARRANGEMENTS-BOER AND ENGLISH.

The absence of proper sanitary regulations in the Boer laager at Stormberg was a disgrace to any nation that pretended to civilisation. Dead animals and the remains of slaughtered sheep and oxen lying about unburied caused a terrible stench. In the offices and waiting-rooms at the railway stations all sorts of refuse were allowed to accumulate, and in some instances dead horses were left behind inside the railway offices. There was a good deal of sickness and at least two fatal cases of enteric fever occurred among the Boer forces at Stormberg. At the same time the sanitary arrangements for our troops who were stationed in, or who passed through, the district were not free from reproach. At the Bethulie Bridge camp the stench along the river bank and for some considerable distance from the river was bad. The same thing was noticeable at Sterkstroom camp. At Burghersdorp station at the time when large numbers of troops were passing through, according to the stationmaster on more than one morning the station yard was in a disgusting state. These things ought not to be. Proper sanitary arrangements for large bodies of troops in transit may be difficult to arrange, but surely some steps could be devised which would obviate such a state of affairs as that just mentioned. With reference to the camps there is less excuse ; either the sanitary arrangements must have been at fault, or the discipline for their proper enforcement must have been lax. Many of the cases of typhoid fever which have occurred among our troops lately may have been unavoidable-for instance, in the case of the men surrounding Cronje's laager at Paardeberg-but other cases have probably occurred which might have been avoided by more attention to sanitary arrangements and stricter discipline in this matter. At Bethulie Bridge the water from the Orange river was used for drinking purposes. My opportunities for observations regarding military sanitary arrangements have been confined to this district. It is to be hoped that elsewhere matters were better regulated.

THE OBJECT OF THE WAR.

From the talk of the farmers and Free Staters there is no doubt that the object of this war was aggressive not defensive - to get rid of English authority and government from the whole of Sonth Africa. At a Bond meeting held in this district about a year ago one speaker said that he prayed that the day might come when the whole of Africanderdom would be free from the foreign yoke. No one made any protest against this statement. One of the Free State commandants addressing a number of recruits on the market square of Burghersdorp last November said, "We have come to assist you in throwing off the foreign yoke." Very little was heard of saving the independence of the Republics, but the common talk among the farmers was of "cleaning the land" or "driving the British into the sea." The Dutch farmers were urged to join in a triumphal progress through the colony, in which no serious opposition was expected from any British troops. They were told by Free Staters that it would be only a matter of a few weeks and that 
erery district which they reached they would be joined by large numbers of Africanders, and they talked of drinking champagne in Cape Town over their conquest within a month. With the great majority of the burghers their confidence of success was absolute. One burgher said that after they had killed all the English soldiers General Joubert would hire a ship and they would send him and his men to England to fetch "Victoria" out of her house and bring her to the jail at Pretoria.

BOER NEWS-OFFICIAL AND OTHERWISE.

An information commission at Bloemfontein sent out official telegrams recording the progress of the war. On the whole the news was reliable, but in one point these official telegrams consistently perverted the trutb. They grossly exaggerated the casualties on the British and always understated those on the Republican side. For instance, after Belmont the official telegram stated the Boer losses as ten killed and 40 wounded, and said that the British losses were estimated at far in excess of 2000 . In this instance they seem to have divided their actual losses in killed by ten whereas they multiplied ours by about the same figure. Current gossip exaggerated the British casnalties still further. We were said to have lost 7000 or more men at Belmont. At Magersfontein we were reported to have lost 9000 killed, and the blood had run four feet deep. The man who brought this report said that he had it from the lips of a minister of the Datch Church so that it must be true. our losses were heavy but when they were exaggerated to this extent it is not to be wondered at that the Dutch farmers imagined that there was little chance of British success in this war. When the news of the naval brigade fighting under Methuen reached them it was said that England evidently had no more soldiers to send and was sending sailors to fight now.

\section{CONCLUSION.}

In justice to the Free State officials it is only fair to state that in Burghersdorp the English residents were on the whole very fairly treated. Among the Free State burghers drunkenness was certainly less in evidence than with our own men. The liquor regulations during the Boer occupation were more stringent. As soon as the town was re-occupied the difference in this respect was painfully brought to our notice.

\section{TACHYCARDIA FOLLOWING ENTERIC FEVER.}

BY CHARLES BURLAND, M.D. BRUX., F.R.G.S., LATK PRESIDENT OF THE BRUSSELS GRADUATES' ASSOCIATION, PRINCIPAI MEDICAL OFFICER TO H.M. HOSPITAL I'RAYSPORT, NO. 77.

THE subjoined synopsis of cases of enteric fever and dysentery which recently came under my care as medical officer in charge of one of the hospital transports from South Africa to Southampton, and the preponderance of typhoid fever cases will, I trust, plead my excuse for submitting a somewhat extensive and varied personal experience to the readers of THE LANCET.

There were under my care, out of a total of 632 patients, 265 cases of enteric fever and 82 cases of dysentery. All these patients had been discharge $d$ direct from hospital to the steamer in the early stages of convalescence, and one pronounced symptom which was present in the majority of cases greatily impressed me; this was an unusually rapid, small, and compressible pulse peculiar to the enteric fever cases, associated with signs of early cardiac dilatation. For purposes of investigation I enlisted the help of SurgeonCaptain Fenwick of the New Zealand Mounted Infantry and we made a careful and exhaustive examination of 300 cases of enteric and dysenteric convalescents. In every case in which the pulse-rate exceeded 90 the heart was examined binaurally by Surgeon-Captain Fenwick and myself.

Roughly gauging the severity of the illness by the past military history, as regards work and hardships; having regard, in the case of civilian soldiers, to the sufferer's previous occupation and habitual mode of life; calculating the number of weeks which were spent in hospital; and atter prolonged and searching individual examination we obtained the following results. The lowest pulse-rate in the military enteric fever cases was 72 per minute and the highest was 150, an average exactly of 98-25. In 56 per cent. the pulse-rate was 80 ; in 25 per cent. it was 95 ; in 10 per cent. it was 100 ; in 5 per cent. it was 110 ; and in 4 per cent. it was from 120 to 140 .

In investigating 50 cases of dysentery we found an average pulse-rate which varied from 72 to 80 . The number of hearts examined was 75 per cent. of the total cases. In five cases valvular disease was present and these were excluded. In 25 per cent. of those examined the apex beat was displaced. In 50 per cent. the impulse was diffused, undula. tory, and difficult to localise. A feeble first sound and a sharp and accentuated second sound were frequent features, while in a small percentage of cases undoubted dilatation was present.

The following is an interesting case illustrating the points which I wish to bring forward.

A Scots Guardsman, aged 30 years, a man of superb physique, came on board apparently convalescent. Seven days later he collapsed suddenly on deck and was at once placed in his cot. His condition was so serious that I summoned Dr. Atherstone, assistant medical officer, in early consultation. The pulse at this time was 150 , and was thin and compressible. Dyspncea was distressing, the face was pinched, cold, and markedly blanched, while the body was covered with a clammy sweat. The patient complained of acute abdominal pain and the abdomen was tympanitic but not rigid. The pain on deep-seated epigastric pressure was excruciating. I was inclined to regard the case as one of acute cardiac failure, but as there seemed to be a possibility of perforation-these men take every opportunity of eating forbidden food surreptitiously-I asked Surgeon-Captain Fenwick for the benefit of his surgical experience. It was decided to continue the medical treatment. The patient rallied slightly under a very free exhibition of stimulants, but expired 36 hours after his first seizure.

The post-mortem examination, one hour after death, revealed enlargement of the heart with dilatation of the left ventricle. The valves were healthy; the lungs were deeply congested; the abdomen was healthy; there was no perforation; and the cardiac walls, left ventricle especially, were very thin. The finger readily perforated the heart substance on slight pressure.

My experience of typhoid fever had hitherto, I confess, led me to coincide with the views of the recognised Englist and American authorities on the slow pulse usually found in convalescent patients from this disease, and it was certainly startling to find that of all my convalescents not 2 per cent. had a pulse-rate below 70 .

How can this rapid pulse-rate in military patients be accounted for? Surgeon-Captain Fenwick adduced a theory of sympathetic irritation which I could not bring myself to accept, but which nevertheless recalled cases of physical exhaustion and cardiac disturbance with rapid, feeble pulse due to hardship and privation, which $I$, in common with other travellers, have found associated with mountain sickness upon the Himalayas, similarly with well-known phenomena which occasionally prevail in the collapse attending persistent and aggravated sea-sickness. It must, of course, be remembered that in the enteric fever cases which I now portray the majority of the patients had been grievously debilitated by fatiguing marches and poor and irregular feeding - thus engendering a state of cardiac irritation which the subsequent typhoid fever had not conduced to allay. May we not assume that the symptoms described are the natural and inevitable sequelæ of such conditions?

I have selected the following cases of relapsing enteric fever and dysentery, my object being to show that although the dysenteric attacks equalled the enteric in severity, yet in the former disease the pulse-rate was markedly slower.

CASE 1.-An officer, aged 27 years, who went through the whole siege of Kimberley, where he distinguished himself by his unceasing energy, had an attack of typhoid fever and was in due course invalided home. Surgeon-Captain Fenwick, who knew him intimately, stated that be was apparently quite convalescent when discharged from Wynberg Hospital. The patient complained of feeling ill directly be reached the ship and was admitted to hospital treatment at once. After a trying illness, which presented all the features of a severe primary attack but which were unquestionably due to a terribly bad relapse, he suddenly had an attack of cardiac failure on the fifth day of the homeward voyage. He was extremely ill throughout the remainder of the journey 